\title{
PROPYLENE GLYCOL PHARMACOKINETICS AND RENAL ELIMINATION CAPACITY:
} PRELIMINARY OBSERVATIONS

\author{
A. Kulo ${ }^{1,2}$, V. Cossey ${ }^{3}$, J.N. de Hoon ${ }^{1}$, R. Verbesselt ${ }^{1}$, K. Allegaert $^{3}$ \\ ${ }^{I}$ Center for Clinical Pharmacology, University Hospitals Leuven, Leuven, Belgium, ${ }^{2}$ Institute of \\ Pharmacology, Clinical Pharmacology and Toxicology, University of Sarajevo, Sarajevo, Bosnia- \\ Herzegovina, ${ }^{3}$ Paediatrics, University Hospitals Leuven, Leuven, Belgium
}

Introduction: Unintended propylene glycol (PG) administration $(34 \mathrm{mg} / \mathrm{kg} / 24 \mathrm{~h})$ did not affect postnatal adaptations [1]. Subsequently, we aim to document PG disposition in neonates.

Methods: Blood and urine samples were collected in neonates to whom PG was co-administered (Paracetamol Synthetica ${ }^{\circledR}$, Mendrisio, Italy). Plasma and urine samples were collected in the first six hours after the first drug administration (loading dose, $20 \mathrm{mg} \cdot \mathrm{kg}^{-1}$ paracetamol, equal to $16 \mathrm{mg} \mathrm{PG} \mathrm{kg}{ }^{-1}$ ). An earlier described reversed phase liquid chromatographic (LC) method with ultraviolet detection was optimized for chromatographic separation.

Results: Chromatographic separation resulted in cleaner chromatograms without interfering compounds. Linearity, variations in the intra-and inter-assay precision and accuracy and stability at different temperature conditions were satisfactory. The lower limit of quantification $\left(0.25 \mathrm{mg} . \mathrm{L}^{-1}\right)$ was twenty times lower than in earlier described methods. The method was suitable for quantification of PG concentrations in low volume plasma (15-46 mg. $\left.\mathrm{L}^{-1}\right)$ and urine samples (20-175 mg. $\left.\mathrm{L}^{-1}\right)$, strongly indicating difference between neonates and adults in the relative contribution of the renal (7.02\%) compared to the metabolic route for PG elimination. Assuming a one-compartment model, peak concentrations were around $40 \mathrm{mg} \cdot \mathrm{L}^{-1}$, suggesting a distribution volume of $0.5{\mathrm{~L} . \mathrm{kg}^{-1}}^{-1}$ while the elimination half life was estimated to be $6-12 \mathrm{~h}$.

Conclusion: An accurate and sensitive LC method was developed, and applied to determine PG in low volume neonate plasma and urine samples, enabling us to estimate the renal versus non-renal contribution of PG clearance in neonates.

[1] Allegaert K et al. Arch Dis Child 2010;95:1054-1058 